\title{
PENGARUH KREDIBILITAS PETUGAS TERHADAP SIKAP KEPATUHAN PASIEN TUBERKULOSIS PADA PEMERIKSAAN DAHAK
}

\author{
Egie Jatnika Kosasih ${ }^{1}$, Yanti Setianti ${ }^{2}$ dan Uud Wahyudin ${ }^{2}$ \\ ${ }^{1}$ Dinas Kesehatan Kabupaten Bandung Barat \\ ${ }^{2}$ Universitas Padjadjaran
}

\begin{abstract}
ABSTRAK
Tujuan penelitian ini adalah untuk mengetahui pengaruh kredibilitas petugas Tuberkulosis terhadap sikap kepatuhan pasien tuberkulosis pada pemeriksaan dahak di akhir bulan kedua. Metode penelitian yang digunakan adalah kuantitatif dengan menggunakan studi analisis jalur di puskesmas wilayah kabupaten Bandung Barat. Populasi dalam penelitian ini adalah seluruh pasien puskesmas di wilayah Kabupaten Bandung Barat yang tidak melakukan pemeriksaan dahak di akhir bulan kedua. Sampling yang digunakan pada penelitian ini adalah probability random sampling dengan jumlah sampel sebanyak 87 orang. Lokasi penelitian ini adalah Puskesmas yang berada di wilayah Kabupaten Bandung Barat. Metode analisis yang digunakan dalam penelitian ini adalah analisis tabel dan analisis statistic (analisis jalur). Hasil dari penelitian ini menunjukkan bahwa kredibilitas petugas Tuberkulosis yang diukur dengan keahlian dan kepercayaan berpengaruh terhadap sikap kepatuhan pasien Tuberkulosis pada pemeriksaan dahak di akhir bulan kedua. Keahlian dan kepercayaan pasien kepada petugas tuberkulosis memiliki pengaruh yang cukup besar untuk menjamin pasien melakukan pemeriksaan dahak pada akhir bulan kedua. Sarannya diharapkan petugas dapat mempertahankan dan meningkatkan keahlian serta meningkatkan kepercayaan yang dinilai pasien masih belum maksimal.
\end{abstract}

Kata-kata Kunci: Kepatuhan pasien, kredibilitas, sikap, sikap kepatuhan pasien, tuberkulosis

\section{THE EFFECT OF TUBERCULOSIS HEALTH WORKERS CREDIBILITY TO TUBERCULOSIS PATIENT COMPLIANCE ON SPUTUM TEST}

\begin{abstract}
The purpose of this study was to determine the effect of Tuberculosis (TB) health workers credibility to Tuberculosis patient compliance on sputum test at the end of second month. The research method was quantitative. The population in this study was all patients from primary health centers in West Bandung Regency who did not perform sputum test at the end of the second month. This study used probability random sampling with total sample as many as 87 people. The location of this study was at primary health centers in West Bandung Regency. The analytical method conducted in this research was table and statistic analysis (path analysis). The results of this study showed that TB health workers credibility which was measured with expertise and confidence influenced TB patient compliance on sputum test at the end of second month. Expertise of health workers and patient trust had considerable impact to convince the patients to do sputum test at the end of the second month. Suggestion from the result of this study that TB health workers could maintain and improve both skill and ability to increase the trust with TB patients.
\end{abstract}

Keywords: Compliance patients, credibility, attitude, attitude compliance patients, tuberculosis

Korespondensi: Egie Jatnika Kosasih S.Km., M.I.Kom. Dinas Kesehatan Kabupaten Bandung Barat. Komplek Perkantoran Pemda Ds. Mekarsari Kec. Ngamprah Kab. Bandung Barat 40552. Email: egie. kesmas@gmail.com 


\section{PENDAHULUAN}

Komunikasi berperan penting dalam menunjang keberhasilan setiap program yang dijalankan di bidang kesehatan baik itu program yang sifatnya pencegahan (preventif), pengobatan (kuratif), peningkatan (promotif) dan perbaikan (rehabilitative). Salah satu dari sekian banyak program yang dilakukan di bidang kesehatan diantaranya program pengendalian dan penanggulangan tuberkulosis dengan salah satu kegiatannya dikenal dengan istilah AKMS (Advokasi, Komunikasi dan Mobilisasi Sosial).

Program advokasi komunikasi dan mobilisasi sosial ini akan berhasil apabila ditunjang dengan kredibilitas dari seorang petugas tuberkulosis. Semakin kredibelnya seorang petugas tuberkulosis, maka pasien semakin percaya dengan apa yang disampaikan dan nantinya akan menuruti apa yang diperintahkan oleh petugas tersebut. Dengan berhasilnya program kegiatan advokasi, komunikasi dan mobilisasi sosial diharapkan dapat menurukankan angka kejadian tuberkulosis terutama di wilayah Kabupaten Bandung Barat (Depkes, 2011).

Penyakit tuberkulosis atau yang sering disebut TBC adalah penyakit infeksi menular yang disebabkan oleh bakteri mycobacterium tuberculosis. Bakteri ini merupakan bakteri basil yang sangat kuat sehingga memerlukan waktu yang lama untuk mengobatinya. Tuberkulosis merupakan masalah kesehatan, baik dari sisi angka kematian (mortalitas), angka kejadian penyakit (morbiditas), maupun diagnosis dan terapinya. Indonesia saat ini berada pada ranking kelima negara dengan beban TB tertinggi di dunia (2011).

Penyakit Tuberkulosis (TBC) sampai saat ini masih menjadi masalah kesehatan masyarakat karena merupakan salah satu penyakit infeksi pembunuh utama yang menyerang golongan usia produktif (15-50 tahun) dan anak-anak serta golongan sosial ekonomi lemah (Komariah, 2016).

Pemeriksaan dahak di akhir bulan kedua adalah bagian dari kegiatan advokasi, komunikasi dan mobilisasi sosial yaitu kegiatan pemeriksaan dahak yang dilakukan oleh pasien yang mempunyai gejala tuberkulosis dimana mereka memeriksakan dahaknya pertama kali dan setelah dua bulan pasien tersebut diminta datang lagi ke Puskesmas untuk diperiksa kembali dahaknya oleh petugas tuberkulosis. Pemeriksaan dahak diakhir bulan kedua ini merupakan salah satu cara yang bisa dilakukan untuk mewujudkan keberhasilan dalam penanggulangan penyakit tuberkulosis dimana pemeriksaan dahak yang dilakukan pada akhir bulan kedua menentukan pengobatan jenis apa yang akan dilakukan selanjutnya.

Petugas tuberkulosis adalah seorang petugas kesehatan yang ada di Puskesmas yang ditunjuk oleh Kepala Puskesmas untuk memegang program tuberkulosis dari mulai perencanaan, pelaksanaan pelayanan \& evaluasi dengan latar belakang pendidikan berbedabeda ada yang perawat dan analis kesehatan. Jenis komunikasi yang digunakan oleh petugas adalah komnikasi antar pribadi dengan salah satun tujuannya adalah agar pasien yang sudah diperiksakan dahak pertama kalinya patuh untuk melakukan pemeriksaan dahak di akhir bulan kedua, hal ini merupakan langkah yang harus dilalui oleh seorang pasien tuberkulosis untuk dapat menentukan jenis pengobatan apa yang bisa dilakukan karena apabila pasien tidak patuh dikhawatirkan akan timbul Multy Drug Resistance atau kekebalan terhadap obat-obat tuberkulosis.

De Vito mendefinisikan komunikasi antar pribadi merupakan pengiriman pesan-pesan dari seseorang dan diterima oleh orang lain, atau sekelompok orang dengan efek dan umpan balik yang langsung (Liliweri, 1991: 13). Dalam setiap kegiatan komunikasi antar pribadi selalu melibatkan orang sebagi organ pelaksana dalam penyampaian pesan, karenanya agar pesan yang disampaikan oleh komunikator dapat memberikan hasil yang lebih baik, dapat digunakan teknik persuasif. Adapun teknik persuasif yang dimaksud dalam hal ini adalah suatu kegiatan dalam upaya membujuk komunikan agar melakukan atau berbuat sesuai dengan maksud dan tujuan komunikator.

Berbicara tentang komunikator atau sumber informasi, ada faktor yang disebut dengan kredibilitas sumber. Dimana sumber informasi dalam pengobatan tuberkulosis adalah petugas tuberkulosis Puskesmas yang ada di Kabupaten Bandung Barat. Menurut Jalaluddin Rakhmat, ada dua komponen kredibilitas yang paling penting yaitu keahlian dan kepercayaan. Dimana keahlian ini adalah kesan yang dibentuk oleh komunikate tentang kemampuan komunikator dalam hubungannya 
dengan topik yang dibicarakan. Sedangkan kepercayaan adalah kesan komunikate tentang komunikator yang berkaitan dengan wataknya (Rakhmat, 2008: 260).

"Tahun 2015 dari bulan Januari sampai dengan Juni jumlah pasien tuberkulosis yang memeriksakan dahak di Kabupaten Bandung Barat ada 741 pasien, dimana pasien yang memeriksakan dahak di akhir bulan kedua ada 539 orang dan yang tidak memeriksakan dahak diakhir bulan kedua ada sekitar 202 orang" (Wawancara langsung dengan Didin Samsudin Amd.Ak petugas tuberkulosis Bidang PLP2 Dinkes KBB, tanggal 6 Oktober dan 27 november 2015).

Berdasarkan hasil wawancara dengan 10 pasien yang tidak memeriksakan dahak di akhir bulankedua 7 pasien menyebutkan alasan mereka tidak memeriksakan dahak di akhir bulan kedua adalah dikarenakan petugas tuberkulosis yang dianggap kurang baik dalam menyampaikan pesan tentang pengobatan tuberkulosis adapun salah satu kutipan hasil wawancara dengan pasien yang tidak memeriksakan dahak di akhir bulan kedua diantaranya: "Saya tidak balik lagi ke Puskesmas karena petugas yang di Puskesmas nyuekin saya terus tidak terlalu jelas kalau pas ngobrolnya" (Wawancara langsung dengan Hilman 19 tahun pasien tuberkulosis , tanggal 1 Desember 2015).

Berdasarkan kutipan wawancara dan pernyataan yang disampaikan oleh pasien tersebut, kalimat "nyuekin dan tidak terlalu jelas" disimpulkan oleh peneliti sebagai kata yang ada hubungannya dengan unsur kredibilitas yaitu keahlian dan kepercayaan dari petugas tuberkulosis yang menyebabkan pasien tidak melakukan pemeriksaan dahak di akhir bulan kedua. Menurut Jalaluddin Rakhmat, ada dua komponen kredibilitas yang paling penting yaitu keahlian dan kepercayaan. Dimanan keahlian ini adalah kesan yang dibentuk oleh komunikate tentang kemampuan komunikator dalam hubungannya dengan topik yang dibicarakan. Sedangkan kepercayaan adalah kesan komunikate tentang komunikator yang berkaitan dengan wataknya (Rakhmat, 2008: 260).

Berdasarkan hal tersebut, peneliti tertarik untuk mengkaji kasus ini dari aspek komunikasi dimana hal ini menjadi tantangan bagi petugas kesehatan pada umumnya dan petugas tuberkulosis Puskesmas di wilayah Kabupaten Bandung Barat pada khususnya. Selama ini petugas tuberkulosis berfokus pada apa yang menjadi kelemahan program penanggulangan tuberkulosis, sekarang saatnya petugas tuberkulosis berfikir untuk melihat permasalahan ini dari sudut pandang ilmu sosial yaitu ilmu komunikasi dan diharapkan dapat merumuskan strategi komunikasi apa yang harus dipersiapkan untuk menyukseskan program penanggulangan dan pemberantasan tuberkulosis.

Maksud penelitian adalah untuk mengetahui dan memahami tentang adanya pengaruh kredibilitas petugas tuberkulosis dengan cara menganalisis pengaruh dari faktor-faktor pembentuk kredibilitas, yaitu: keahlian dan kepercayaan terhadap sikap pasien tuberkulosis yang meliputi aspek afeksi, kognisi dan konasi. Sedangkan tujuan penelitian adalah sebagai berikut (1) Untuk mengetahui besar pengaruh faktor keahlian petugas tuberkulosis terhadap sikap pasien tuberkulosis pada pemeriksaan dahak diakhirbulankedua.(2)Untukmengetahui besar pengaruh faktor kepercayaan petugas tuberkulosis terhadap sikap pasien tuberkulosis pada pemeriksaan dahak di akhir bulan kedua. (3) Untuk mengetahui besar pengaruh faktor keahlian dan kepercayaan petugas tuberkulosis secara bersama-sama terhadap sikap pasien tuberkulosis pada pemeriksaan dahak di akhir bulan kedua.

Teori aplikasi yang digunakan dalam penelitian ini adalah teori kredibilitas sumber yang dikemukakan oleh Hovland, Janis dan Kelley (Source Credibility Theory) dalam buku Communication and Persuasion.

"High credibility sources had a substantially greater immediate effect on the audience's opinions than low credibility sources" (Hovland, Janis \& Kelly, 1968: 270). Sumber dengan kredibilitas tinggi memiliki dampak besar terhadap opini audiens daripada sumber dengan kredibilitas rendah. Sumber yang memiliki kredibilitas tinggi lebih banyak menghasilkan perubahan sikap dibandingkan dengan sumber yang memiliki kredibilitas rendah.

Asumsi dasar dari teori ini adalah menyatakan bahwa seseorang dimungkinkan lebih mudah dipersuasi jika sumber-sumber persuasinya cukup kredibel. Seseorang akan 
lebih percaya dan cenderung menerima dengan baik sebuah pesan yang disampaikan oleh orang yang memiliki kredibilitas di bidangnya.

Hovland dan Weiss dalam Tan (1981: 113) menyebutkan: "High credibility sources produce more attitude change than low credibility sources". Sumber dengan kredibilitas tinggi dapat merubah kebiasaan orang lain dibandingkan dengan sumber yang mempunyai kredibilitas rendah.
Dua komponen kredibilitas yang paling penting adalah keahlian dan kepercayaan. Keahlian adalah kesan yang dibentuk komunikate tentang kemampuan komunikator dalam hubungannya dengan topik yang dibicarakan. Komunikator yang cerdas, mampu, ahli, tahu banyak, berpengalaman dan terlatih dinilai tinggi keahliannya. Sedangkan kepercayaan adalah kesan komunikate tentang komunikator yang berkaitan dengan wataknya

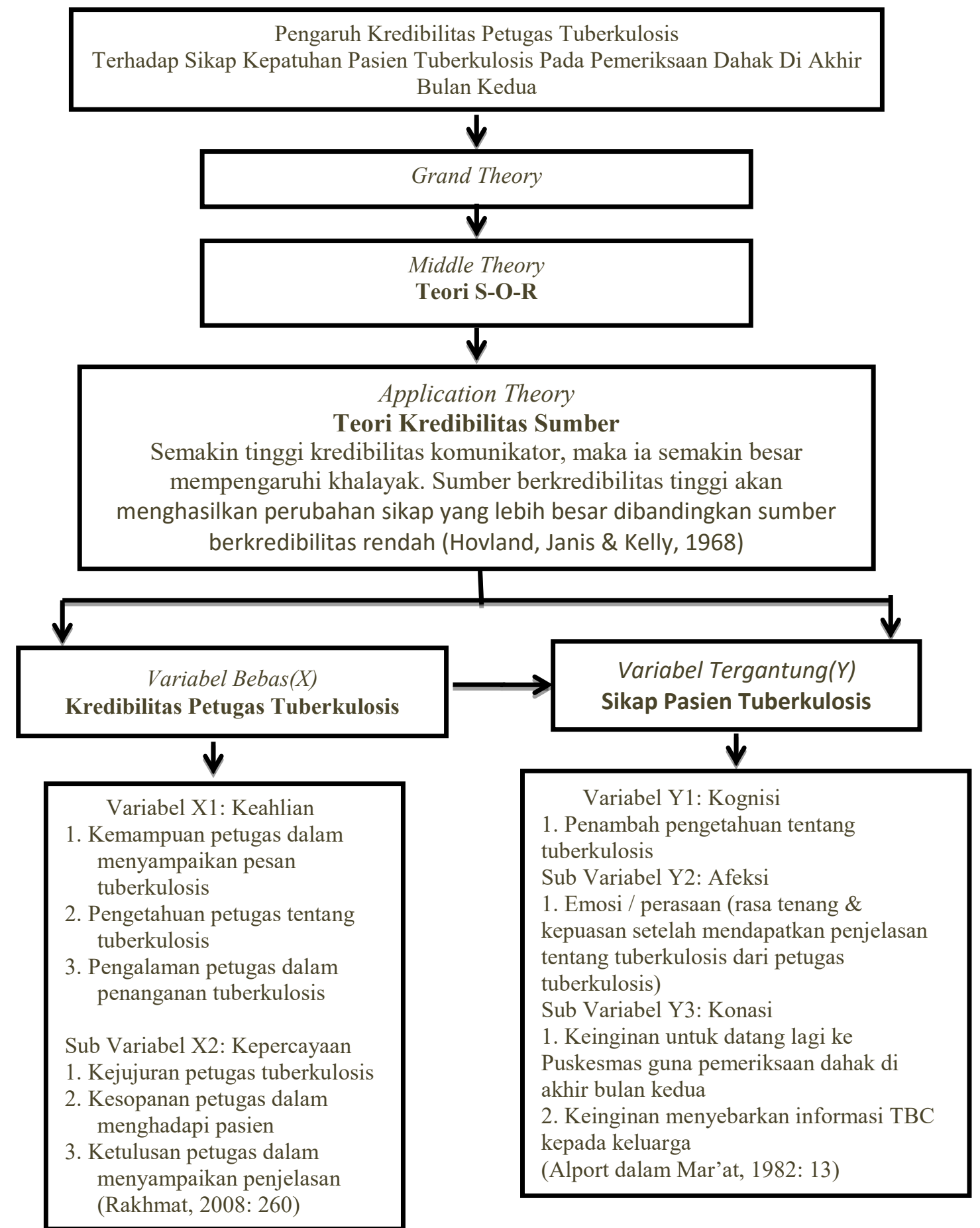

Sumber: Mar'at (1982: 13), (Hovland, Janis \& Kelly, 1968) \& modifikasi penulis 
termasuk didalamnya jujur, tulus, bermoral, adil, sopan dan etis (Rakhmat, 2008: 260).

Pasien tuberkulosis adalah seseorang yang mempunyai keluhan atau gejala klinis mendukung tuberkulosis. Secara umum gejala penderita tuberkulosis paru adalah batuk berdahak dan kadang-kadang batuk berdarah, lesu, dan sesak nafas, berkeringat dingin pada waktu malam hari tanpa ada kegiatan, demam lebih dari satu bulan, nafsu makan dan berat badan menurun.

Sikap merupakan suatu yang komplek, dapat didefinisikan sebagai pernyataanpernyataan evaluatif, baik yang menyenangkan maupun yang tidak menyenangkan, atau penilaian mengenai objek, manusia atau peristiwa- peristiwa. Sikap yang kompleks ini dapat lebih mudah dimengerti dengan mengenal adanya tiga komponen yang berbeda dalam setiap sikap tertentu, yaitu komponen kognitif, afektif dan konatif.

Menurut Kamus Bahasa Indonesia Modern, patuh adalah suka menurut perintah, taat pada perintah, sedangkan kepatuhan adalah perilaku sesuai aturan dan berdisiplin. Kepatuhan adalah suatu bentuk perilaku yang timbul akibat adanya interaksi antara petugas kesehatan dan pasien sehingga pasien mengerti rencana dengan segala konsekwensinya dan menyetujui rencana tersebut serta melaksanakannya (Kemkes RI,
2011).

Pemeriksaan dahak di akhir bulan kedua adalah pemeriksaan dahak yang dilakukan oleh pasien tuberkulosis yang terdiagnosa BTA positif untuk kedua kalinya setelah psien tersebut diperiksa dahaknnya untuk pertama kali dua bulan sebelumnya oleh petugas pengelola program tuberkulosis di Puskesmas.

\section{METODE PENELITIAN}

Dalam penelitian ini peneliti menggunakan metode survei eksplanatoris. Menurut Singarimbun dan Effendy (1989: 5), metode survei eksplanatoris bertujuan menjelaskan hubungan kausal dan pengujian hipotesis, melalui data akan dijelaskan hubungan kausal antara variabel-variabel melalui pengujian hipotesis. Metode penelitian ini mengambil sampel dari suatu populasi kemudian akan menggunakan kuisioner sebagai alat pokok dalam pengumpulan data dengan analisis jalur (path analysis) dan menggunakan metode korelasional.

Variabel bebas dalam penelitian ini adalah kredibilitas petugas tuberkulosis. Kredibilitas ini dioperasionalkan sebagai berikut: (a) Keahlian petugas tuberkulosis yang dilambangkan dengan X1. (b) Kepercayaan petugas tuberkulosis yang dilambangkan

Tabel 1 Operasional Variabel Penelitian

\begin{tabular}{|c|c|c|c|}
\hline Variabel Konstruk & Dimensi & Indikator & Skala \\
\hline \multirow{6}{*}{$\begin{array}{l}\text { Kredibilitas Petugas } \\
\text { Tuberkulosis (X) }\end{array}$} & \multirow{3}{*}{$\begin{array}{l}\text { Keahlian Petugas } \\
\text { tuberkulosis }\end{array}$} & - Kemampuan & \multirow[t]{3}{*}{ Ordinal } \\
\hline & & - Pengetahuan & \\
\hline & & - Pengalaman & \\
\hline & \multirow{3}{*}{$\begin{array}{l}\text { Kepercayaan Petugas } \\
\text { tuberkulosis }\end{array}$} & - Dapat dipercaya & \multirow{3}{*}{ Ordinal } \\
\hline & & - Dapat diandalkan & \\
\hline & & - Ketulusan dalam pelayanan & \\
\hline \multirow{6}{*}{$\begin{array}{l}\text { Sikap Pasien } \\
\text { Tuberkulosis (Y) }\end{array}$} & \multirow{2}{*}{ Kognisi } & - Persepsi & \multirow[t]{2}{*}{ Ordinal } \\
\hline & & - Menambah pengetahuan & \\
\hline & \multirow{2}{*}{ Afeksi } & - Emosi & \multirow[t]{2}{*}{ Ordinal } \\
\hline & & - Perasaan & \\
\hline & \multirow{2}{*}{ Konasi } & $\begin{array}{l}\text { - Kesediaan untuk memeriksakan } \\
\text { kembali dahak di akhir bulan } \\
\text { kedua }\end{array}$ & \multirow[t]{2}{*}{ Ordinal } \\
\hline & & $\begin{array}{l}\text { - Kesediaan untuk menyebarkan } \\
\text { informasi penyakit TBC kepada } \\
\text { keluarganya }\end{array}$ & \\
\hline
\end{tabular}


dengan X2. Variabel terikat dalam penelitian ini adalah sikap pasien tuberkulosis dalam pemeriksaan dahak di akhir bulan kedua. Sikap adalah keteraturan tertentu dalam hal pemikiran (kognisi), perasaan (afeksi) dan kecenderungan bertingkah laku (konasi) seseorang terhadap suatu aspek di lingkungan sekitarnya.

Populasi dalam penelitian ini adalah pasien yang tidak melakukan pemeriksaan dahak di akhir bulan kedua. Berdasarkan laporan tuberkulosis di wilayah Dinas Kesehatan Kabupaten Bandung Barat pada bulan Januari sampai dengan Juni tahun 2015 ada 202 pasien. Teknik pengambilan sampel yang digunakan adalah teknik sampling sistematik. Teknik sampling sistematik adalah sebuah metode sampling yang memiliki metode seleksi dengan mengacu pada pedoman aturan sistematik, hanya pada seleksi unit sampel yang pertama saja menggunakan cara acak, namun untuk selanjutnya menempatkan atau menggunakan pedoman aturan sistematik (Prijana, 2005: 20). Ukuran sampel yang digunakan dalam penelitian ini adalah sebanyak 87 pasien yang ada di Puskesmas wilayah Kabupaten Bandung Barat.

Penelitian dilakukan di lokasi tempat tinggal pasien atau di Puskesmas yang tersebar di 15 Kecamatan yang berada di wilayah Kabupaten Bandung Barat. Pelaksanaan penelitian dilakukan dari bulan Agustus 2015 sampai dengan April 2016.

\section{HASIL DAN PEMBAHASAN}

Berdasarkan jenis kelamin, lebih dari setengah dari responden $(55,2 \%)$ berjenis kelamin laki-laki atau sebanyak 48 orang responden, sedangkan hampir setengahnya dari responden penelitian $(44,8 \%)$ berjenis kelamin perempuan atau sebanyak 39 orang responden. Seperti yang diungkapkan oleh Rosady (1985, 319) bahwa "perbedaan jenis kelamin tersebut akan membawa perbedaan dalam tingkah laku, watak, perasaan, dan dalam beberapa tugas kewajiban". Seperti kita ketahui bahwa lakilaki adalah tulang punggung keluarga dimana tugas dan kewajiban mereka lebih memerlukan aktivitas fisik yang lebih banyak dibandingkan dengan perempuan, sehingga ketika fisiknya lemah dan bakteri tuberkulosis ada di lingkungan, maka laki-laki akan lebih mudah terjangkit penyakit tuberkulosis.
Pembagian masa dewasa menurut Hurlock yang dikutip oleh Wahyunari (2011: 80-81) adalah sebagai berikut: (1) Masa dewasa dini, yaitu dimulai pada umur 18 tahun sampai dengan kira-kira umur 40 tahun, saat perubahan-perubahan fisik dan psikologis yang menyertai berkurangnya kemampuan reproduktif, (2) Masa dewasa dini madya, yaitu dimulai dari umur 40 tahun sampai pada umur 60 tahun, yakni saat menurunnya kemampuan fisik dan psikologis yang jelas nampak pada setiap orang, dan (3) Masa dewasa lannjut atau usia lanjut, yakni dimulai pada umur 60 tahun sampai dengan kematian. Namum dalam hal berpakaian dan dandanan memungkinkan pria dan wanita berpenampilan dan bertindak seperti mereka masih muda.

Rentang usia 18 sampai 60 tahun termasuk kedalam usia dewasa yang terbagi ke dalam dewasa dini, madya dan lanjut dimana usia tersebut didalamnya sudah banyak perubahan baik fungsi maupun bentuk tubuh seseorang termasuk penurunan daya tahan tubuh seseorang. Ketika daya tahan tabuh sesorang berkurang, maka bakteri akan mudah masuk ke dalam tubuh manusia termasuk bakteri tuberkulosis. Berdasarkan hasil penelitian dari setengah dari responden yaitu 42 orang $(51,7 \%)$ berusia $26-50$ tahun, 28 orang berusia $18-25$ tahun $(32,2 \%)$, 16 orang berusia lebih dari 50 tahun $(18,4 \%)$, dan 1 orang kurang dari 17 tahun.

Berdasarkan distribusi jenis pekerjaan, ada 59 responden yang berprofesi sebagai pegawai pada instansi swasta dan merupakan terbanyak yang menderita penyakit tuberkulosis. Instansi swasta disini kebanyakan sebagai karyawan di perusahaan yang belum terlalu besar sehingga kesejahteraan mereka boleh dikatakan kurang. Ketika kesejahteraan mereka kurang, maka hal tersebut akan berhubungan dengan pemenuhan kebutuhan gizi yang dapat menyebabkan penurunan daya tahan tubuh yang menimbulkan cepatnya terserang penyakit tuberkulosis.

Berdasarkan jenjang pendidikan, diperoleh data distribusi responden paling banyak pasien berpendidikan SMP atau sederajat (33 orang atau $37,9 \%$ ), kemudian SD atau sederajat (27 orang atau 31\%), lalu SMA atau sederajat (26 orang atau 29,9\%), baru disusul dengan S1 (1 orang atau $1,1 \%$ ). Hal tersebut dapat dianalisa bahwa pendidikan berhubungan dengan pekerjaan dan kesejahteraan yang mengakibatkan pola hidup mereka kurang baik menurut kesehatan, 
sehingga memudahkan mereka terinfeksi penyakit tuberkulosis.

Berdasarkan hasil penelitian, tingkat kredibilitas petugas tuberkulosis menurut pasien $(\mathrm{X})$ dinilai tinggi yaitu sebanyak $51,7 \%$ atau 45 orang. Sedangkan $48,3 \%$ responden lainnya yaitu sebanyak 42 orang menilai tingkat kredibilitas petugas tuberkolosis berada pada kategori sedang.

Kredibilitas merupakan suatu image atau gambaran audiens mengenai kepribadian komunikator. Seorang pendengar akan mendengarkan komunikator yang dia nilai memiliki kredibilitas yang tinggi (Liliweri dalam Nurtyasrini dan Hafiar, 2016: 227). Teori kredibilitas pada dasarnya memberikan penjelasan bahwa semakin kredibel sumber maka akan semakin mudah mempengaruhi cara pandang komunikan. Dengan kata lain kredibilitas seseorang mempunyai peranan yang penting dalam mempersuasi komunikan untuk menentukan pandangannya. Dua komponen kredibilitas yang paling penting adalah keahlian dan kepercayaan (Rakhmat, 2008: 260).

Berdasarkan hasil penelitian, tingkat keahlian petugas tuberkulosis menurut pasien (X1) dinilai tinggi yaitu sebanyak $81,6 \%$ atau 71 orang. Sedangkan $18,4 \%$ responden lainnya yaitu sebanyak 16 orang menilai tingkat keahlian petugas tuberkulosis berada pada kategori sedang.

Keahlian komunikator adalah kesan yang dibentuk komunikan tentang kemampuan komunikator dalam hubungannya dengan topik yang dibicarakan. Komunikator yang dinilai ahli maka dia dianggap sebagai cerdas, mampu, tahu banyak, berpengalaman dan terlatih. Keahlian ditunjukan dengan karakteristik tingkat pendidikan, kecerdasan, wawasan yang luas, penguasaan keterampilan dan pengalaman (Venus, 2009: 57).

Berdasarkan hasil penelitian, tingkat kepercayaan pasien kepada petugas tuberkulosis (X2) dinilai sedang yaitu sebanyak $89,7 \%$ atau 78 orang. Sedangkan $10,3 \%$ responden lainnya yaitu sebanyak 9 orang menilai tingkat kepercayaan pasien kepada petugas tuberkulosis berada pada kategori tinggi.

Mayoritas pasien menyatakan bahwa kepercayaan pasien terhadap petugas tuberkulosis untuk melakukan pemeriksaan lanjutan adalah sedang, dengan kata lain kepercayaan pasien pada petugas untuk melakukan pemeriksaan dahak di akhir bulan kedua adalah biasa saja bahkan cenderung kurang.

Berdasarkan hasil penelitian, hampir seluruhnya yaitu 80 orang responden $(92 \%)$ memberikan respon pada ketegori tinggi tingkat sikap kepatuhan pasien untuk melakukan pemeriksaan dahak pada akhir bulan kedua (Y). Sedangkan hampir sebagian kecil dari sebanyak 7 orang $(8 \%)$ responden memberikan respon pada kategori sedang. Artinya, mayoritas responden penelitian sangat mengapresiasi anjuran petugas tuberkulosis kepada mereka untuk melakukan pemeriksaan lanjutan pada bulan kedua.

Selanjutnya pada tingkat sikap pada aspek kognitif (pengetahuan) pasien mengenai tuberkulosis (Y1), mayoritas responden penelitian menyatakan bahwa pengetahuan mereka terhadap tuberkulosis sudah bertambah baik tentang penyakit tuberkulosis secara keseluruhan terutama tentang pemeriksaan dahak di akhir bulan kedua.

Mayoritas responden (79,3\% atau 68 orang) pada kategoti tingkat sikap pada aspek afeksi (perasaan atau tingkat emosi) pasien mengenai tuberkulosis (Y2) menyatakan bahwa meraka merasa tenang dan puas setelah mendapatkan penjelasan tentang penyakit tuberkulosis, karena mereka akan sembuh apabila mereka disiplin atau patuh pada perintah petugas tuberkulosis Puskesmas. Sedangkan bagi responden yang memberikan respon pada kategori sedang $(19,5 \%$ atau 17 orang) menyatakan bahwa perasaan mereka sudah tenang akan tetapi masih ada sedikit rasa khawatir pada penyakit tuberkulosis yang dideritanya tetapi mereka merasa kurang menyukai penampilan fisik yang dimiliki oleh petugas tuberkulosis yang dinilai kurang rapi dan menarik dan hal ini sangat menggangu mereka karena membuat mereka tidak bersemangat untuk melakukan pemeriksaan lanjutan.

Mayoritas pasien $(65,5 \%$ atau 57 orang) pada kategori tingkat sikap pada aspek konasi (kecenderungan berperilaku) pasien mengenai tuberkulosis (Y3) menyatakan bahwa kecenderungan berperilaku mereka terhadap penyakit tuberkulosis secara keseluruhan tinggi artinya, mayoritas responden penelitian sudah mulai memahami bahwa pasien bersedia untuk melakukan pemeriksaan dahak di akhir bulan kedua serta bagaimana memperlakukan 
diri sebagai pengidap tuberkulosis hingga pada pencegahan penularan penyakit kepada orang-orang terdekat atau keluarga. Sedangkan bagi responden yang memberikan respon pada kategori sedang (34,5\% atau 30 orang) menyatakan bahwa mereka masih kurang memahami penyakit tuberkulosis, hal ini dikarenakan penyampaian informasi yang dilakukan oleh petugas masih kurang baik, dan mereka merasa terganggu dengan penampilan petugas yang kurang rapi.

\section{Tabel 2 Deskriptif Statistik Analisis Jalur}

\begin{tabular}{lccc}
\hline \multicolumn{1}{c}{$\begin{array}{c}\text { Descriptive } \\
\text { Statistics }\end{array}$} & Mean & Std. Deviation & $\mathrm{n}$ \\
\hline Sikap & 32.8276 & 2.80036 & 87 \\
Keahlian & 24.1034 & 2.47327 & 87 \\
Kepercayaan & 20.2759 & 1.90281 & 87 \\
\hline
\end{tabular}

Tabel 2 memperlihatkan rata-rata sikap dari 87 orang pasien adalah 32,83 dengan standar deviasi 2,8 . Sedangkan nilai rata-rata keahlian 24,10 dan standar deviasi 2,47. Serta nilai kepercayaan pasien kepada petugas tuberkulosis adalah 20,28 dengan standar deviasi 1,9.

\section{Tabel 3 Koefisien Korelasi}

\begin{tabular}{llrrr}
\hline & & Sikap & Keahlian \\
& & & \\
Pearson & Sikap & 1.000 & .526 & .637 \\
Correlation & Keahlian & .526 & 1.000 & .518 \\
& Kepercayaan & .637 & .518 & 1.000 \\
\multirow{2}{*}{$\begin{array}{l}\text { Sig. } \\
\text { (1-tailed) }\end{array}$} & Sikap &. & .000 & .003 \\
& Keahlian & .000 &. & .000 \\
& Kepercayaan & .000 & .000 &. \\
N & Sikap & 87 & 87 & 87 \\
& Keahlian & 87 & 87 & 87 \\
& Kepercayaan & 87 & 87 & 87
\end{tabular}

Tabel 3 menunjukkan besaran hubungan subvariabel keahlian dengan sikap pasien adalah 0,526 yang menunjukkan hubungan positif. Hal yang sama juga terjadi pada subvariabel kepercayaan dengan sikap pasien adalah 0,637 menunjukkan nilai positif. Jika disesuaikan dengan skala Guilford maka hubungan yang terjadi antara keahlian petugas tuberkulosis dengan sikap pasien adalah 0,526 yang menunjukkan moderate correlation (hubungan yang sedang), dan tingkat keeratan hubungan yang terjadi antara kepercayaan pasien dengan sikap pasien adalah 0,637 yang menunjukkan moderate correlation (hubungan yang sedang).

Tabel 4 Koefisien Korelasi dan Koefisien Determinasi

\begin{tabular}{llllll}
\hline \multicolumn{4}{c}{ Model Summary } \\
\hline Model & R & R Square & $\begin{array}{c}\text { Adjusted } \\
\text { R Square }\end{array}$ & $\begin{array}{c}\text { Std. Error } \\
\text { of the } \\
\text { Estimate }\end{array}$ & $\begin{array}{c}\text { Durbin- } \\
\text { Watson }\end{array}$ \\
\hline 1 & $.678^{\mathrm{a}}$ & .459 & .446 & 2.08393 & 1.528 \\
a. Predictors: (Constant), kepercayaan, keahlian & \\
b. Dependent Variable: sikap
\end{tabular}

Tabel 4 menunjukkan tingkat keeratan hubungan antar variabel $(\mathrm{R})$ adalah 0,678. Bila disesuaikan dengan skala Guilford maka tingkat keeratan antara kredibilitas petugas dengan sikap pasien menunjukkan moderate correlation (hubungan yang sedang). Artinya, kredibilitas petugas tuberkulosis memiliki hubungan yang sedang dengan kepercayaan pasien tentunya jika dilakukan dengan komunikasi dan pemberian informasi yang benar oleh petugas kepada pasien.

Sedangkan pada skor determinasi (R square) menunjukkan nilai 0,459 , dengan standar eror 1,528 dan tingkat estimasi standar eror bernilai 2,08393. Perlu diketahui bilai standar deviasi $>$ standar eror $(2,80036>2,08393)$, maka model regresi bertindak sebagai prediktor nilai sikap. Artinya, untuk meningkatkan sikap kepatuhan pasien untuk melakukan pemeriksaan dahak di akhir bulan kedua tentunya harus dibarengi dengan peningkatan kredibilitas petugas tuberkulosis khususnya dalam hal keahlian petugas dan kepercayaan pasien kepada petugas.

Koefisien determinasi dilakukan untuk menghitung besarnya pengaruh kredibilitas petugas tuberkulosis terhadap sikap kepatuhan pasien untuk melakukan pemeriksaan dahak pada akhir bulan kedua. Berikut penghitungan koefisien determinasi:

$$
\begin{aligned}
\mathrm{KD} & =\mathrm{x} 100 \% \\
& =0,459 \times 100 \% \\
& =45,9 \%
\end{aligned}
$$

Nilai $\quad 45,9 \%$ menunjukkan bahwa 
keahlian yang dimiliki petugas Tuberkulosis dan kepercayaan yang muncul dari dalam diri petugas memiliki pengaruh $45,9 \%$ terhadap sikap pasien. Sedangkan sisanya $54,1 \%$ dipengaruhi faktor lainnya. Sedangkan skor estimasi standar eror sebesar 1,528, perlu diingat bahwa semakin kecil estimasi standar eror maka akan membuat model regresi semakin tepat dalam memprediksi variabel dependen.

\section{Tabel 5 Uji F}

\begin{tabular}{lccccc}
\hline \multicolumn{7}{c}{ ANOVA $^{\mathrm{b}}$} & & \\
Model & $\begin{array}{c}\text { Sum of } \\
\text { Squares }\end{array}$ & Df & $\begin{array}{c}\text { Mean } \\
\text { Square }\end{array}$ & F & Sig. \\
\hline Regression & 309.622 & 2 & 154.811 & 35.648 & $.000^{\mathrm{a}}$ \\
1 Residual & 362.792 & 84 & 4.343 & & \\
Total & 647.414 & 86 & & & \\
\hline
\end{tabular}

a. Predictors: (Constant), kepercayaan, keahlian

\section{b. Dependent Variable: sikap}

Pengujian F ini dapat dilakukan dengan pengujian hipotesis seperti berikut:

H0: Tidak terdapat pengaruh secara signifikan antara kepercayaan dan keahlian secara bersaman terhadap sikap kepatuhan pasien tuberkulosis pada pemeriksaan dahak di akhir bulan kedua di puskesmas wilayah Kabupaten Bandung Barat.

H1: Terdapat pengaruh secara signifikan antara kepercayaan dan keahlian secara bersaman terhadap sikap kepatuhan pasien tuberkulosis pada pemeriksaan dahak di akhir bulan kedua di puskesmas wilayah Kabupaten Bandung Barat.

Bila disesuaikan denganhasil penghitungan SPSS pada tabel ANOVA maka, nilai $\mathrm{F}$ tabel $>$ $\mathrm{F}$ hitung $(5,274>4,343)$ atau nilai signifikan $<$ nilai $0,05(0,000<0,05)$ sehingga dapat disimpulkan tolak $\mathrm{H} 0$ dan terima H1. Artinya, satuan regresi dapat dipakai untuk memprediksi sikap pasien yaitu Terdapat pengaruh secara signifikan antara kepercayaan dan keahlian secara bersaman terhadap sikap kepatuhan pasien tuberkulosis pada pemeriksaan dahak di akhir bulan kedua di puskesmas wilayah Kabupaten Bandung Barat.

\section{SIMPULAN}

Keahlian petugas tuberkulosis di Puskemas wilayah Kabupaten Bandung Barat dalam menyampaikan pesan tentang tuberkulosis dan pentingnya pemeriksaan dahak di akhir bulan kedua terhadap sikap kepatuhan pasien tuberkulosis memiliki pengaruh yang cukup besar untuk menjamin pasien tuberkulosis melakukan pemeriksaan dahak pada akhir bulan kedua.

Kepercayaan pasien tuberkulosis kepada petugas tuberkulosis di Puskesmas wilayah Kabupaten Bandung Barat dalam menyampaikan pesan tentang tuberkulosis dan pentingnya pemeriksaan dahak di akhir bulan kedua terhadap sikap kepatuhan pasien tuberkulosis pada pemeriksaan dahak di akhir bulan kedua memiliki pengaruh yang cukup besar untuk menjamin pasien tuberkulosis melakukan pemeriksaan dahak kembali pada akhir bulan kedua.

Keahlian petugas dan kepercayaan pasien tuberkulosis kepada petugas tuberkulosis terhadap sikap kepatuhan pasien tuberkulosis pada pemeriksaan dahak di akhir bulan kedua memiliki pengaruh yang cukup besar untuk menjamin pasien tuberkulosis melakukan pemeriksaan dahak pada akhir bulan kedua.

Saran praktis dari penelitian ini peneliti tujukan terutama bagi pengelola program tuberkulosis baik di tingkat Dinas Kesehatan Kabupaten Bandung Barat maupun Puskesmas di antaranya: (1) Keahlian petugas tuberkulosis sudah baik perlu dipertahankan dan ditingkatkan agar pelayanan terhadap pasien tuberkulosis menjadi lebih baik lagi salah satunya dengan mengadakan bimbingan teknis dan sosialisasi ilmu baru tentang penyakit tuberkulosis dengan mengundang dinas kesehatan provinsi atau kementerian kesehatan, (2) Kepercayaan petugas tuberkulosis perlu diperbaiki karena hasil perhitungan menyebutkan memiliki pengaruh yang cukup besar terhadap kepatuhan pasien pada pemeriksaan dahak di akhir bulan kedua. Mayoritas pasien menilai bahwa petugas belum maksimal dalam cara menyampaikan pesan dan menggunakan bahasa serta penampilan petugas di depan pasien. Salah satu cara yang dapat dilakukan adalah dengan melakukan pelatihan public speaking supaya kepercayaan diri petugas saat menyampaikan pesan menjadi lebih baik, dan (3) Kredibilitas petugas 
tuberkulosis di mata pasien perlu dipertahankan dan ditingkatkan melalui berbagai macam pelatihan untuk meningkatkan keahlian petugas tentang perkembangan penyakit tuberkulosis dan metode pengobatannya dibarengi dengan pelatihan tentang meningkatkan kualitas pelayanan kesehatan dimana didalamnya ada materi tentang komunikasi dan bagaimana berpenampilan fisik yang baik sebagai petugas kesehatan agar bisa lebih menarik dan dapat dipercaya oleh pasien.

Sedangkan saran teoritis yang penulis berikan yaitu disarankan bagi peneliti lain yang ingin melakukan penelitian dengan tema yang sama diharapkan dapat melakukan penelitian lebih mendalam mengenai unsurunsur kredibilitas sumber, dan penelitian dapat dilakukan di tempat yang berbeda dengan harapan nanti hasilnya dapat digeneralisasi.

\section{DAFTAR PUSTAKA}

Cangara, H. (2007). Pengantar ilmu komunikasi. Jakarta: Raja Grafindo Persada.

Hovland, C. I., Janis, I. L., \& Kelley, H. H. (1968). Communication and persuasion. Connecticut. USA: New Haven and London Yale University Perss.

Kementerian Kesehatan Republik Indonesia. (2011). Pedoman nasional penanggulangan tuberkulosis. Jakarta: Kementerian Kesehatan Republik Indonesia.

Kementerian Kesehatan Republik Indonesia. (2011). Rencana Aksi Nasional Advokasi Komunikasi dan mobilisasi sosial pengendalian tuberkulosis. Jakarta: Kementerian Kesehatan Republik Indonesia.

Komariah, K. (2016). Pola Komunikasi Kesehatan Dalam Pelayanan Dan Pemberian Informasi Mengenai Penyakit TBC Pada Puskesmas Di Kabupaten Bogor. Jurnal Kajian Komunikasi. Diakses dari http://www.journal.unpad.ac.id/jkk pada tanggal 27 April 2016.

Liliweri, A. (1991). Komunikasi antar pribadi. Bandung: Citra Aditya Bhakti.

Liliweri, A. (2009). Dasar-dasar komunikasi kesehatan. Yogyakarta: Pustaka Pelajar.

Nurtyasrini, S. \& Hafiar, H. (2016). pengalaman komunikasipemulungtentang pemeliharaan kesehatan diri dan lingkungan di TPA bantar gebang. Jurnal Kajian Komunikasi. Diakses dari http://journal.unpad.ac.id/jkk/ article/view/10437/5329

Prijana. (2005). Metode sampling terapan. Bandung: Humaniora.

Rakhmat, J. (2008). Psikologi komunikasi. Bandung: Remaja Rosdakarya.

Singarimbun, M. \& Effendi, S. (1989). Metode penelitian survey. Jakarta: LP3S.

Tan, A. S. (1981). Mass communication theories and research. Ohio: Grid Publishing Inc.

Venus, A. (2009). Manajemen kampanye. Bandung: Simbiosa Rekatama Media

Wahyunari, I. (2011). Pengaruh kredibilitas telkomsel personal representative terhadap sikap pengunjung dalam menggunakan produk (studi analisis jalur pada booth education center - bandung elektronik center). Bandung: Universitas Padjadjaran 